\title{
INSTRUÇÃO PÚBLICA E REFORMA SOCIAL NA CIDADE DO RIO DE JANEIRO ENTRE 1922 E $1930^{*}$
}

\author{
André Luiz Paulilo \\ Doutorando - Faculdade de Educação/USP
}

\begin{abstract}
Resumo
Este artigo expõe as orientações de uma pesquisa sobre as reformas da instrução pública na cidade do Rio de Janeiro entre 1922 e 1930. As reformas do período, nessa pesquisa, são examinadas sob a perspectiva das orientações e dos objetivos dos grupos que se propuseram desenvolvê-las junto à população. Assim entendidas, as reformas públicas de ensino na década de 1920 eram um instrumental comprometido com a reforma social. Sob essa perspectiva, examinam-se as tarefas que as reformas Carneiro Leão e Fernando de Azevedo tomaram para si. Finalmente, aponta-se o papel central do projeto de sociedade no planejamento da arquitetura, dos programas e das instalações escolares.
\end{abstract}

\section{Pallavras-Chave}

Reforma educacional • Escolarização moderna • História da educação • Educação popular • Políticas públicas

\section{Abstract}

This article discusses research on the public education reforms carried out in the city of Rio de Janeiro between 1922 and 1930. The educational reforms are examined from the perspective of the mindset and objectives of those who proposed to develop the reforms together with the population. From this perspective, the public education reforms of the 1920 s were committed to social reform. Thus, the article analyzes the tasks that Carneiro Leão and Fernando de Azevedo established in their intended reforms. Finally, the article points towards the central role of a project for society as a whole in the architectural, educational and school facilities planned in the reforms.

\section{Keywords}

Educational Reform $\bullet$ Modern Schooling • History of the Education • Popular Education • Public Policies

\footnotetext{
* Este artigo reproduz em parte algumas das discussões iniciais da minha dissertação de mestrado: Reforma Educacional e sistema público de ensino no Distrito Federal na década de 1920. FEUSP, 2001. 230p.
} 


\begin{abstract}
"Dir-se-ia que, formando as legiões trabalhadoras do país mais aptas, pela difusão do ensino primário, ao manejo eficiente dos instrumentos científicos de produção e dando ás classes superiores da sociedade mais firmes e mais lúcidas diretrizes de pensamento, teríamos encontrado a chave solucionadora dos problemas criados pelo predomínio da ignorância popular e da relativa incultura das elites." Azevedo Amaral (O Paíz, nov. 1928)
\end{abstract}

Ao fundo de quase meia década de estado de sítio, que foram os anos de 1922-1926, a historiografia veio perceber um movimento bastante interessante de contestação do poder de Estado, uma resposta às tentativas de consagrar o pacto oligárquico. Os estudos de Boris Fausto, Edgar Carone, Raymundo Faoro, Sérgio Micelli, Daniel Pecáult, Celso Castro, Décio Saes, Leôncio Basbaum, Maria Lígia Coelho Prado, Edgard Salvadore De Deca, Maria Helena Capelato, Angela de Castro Gomes e Nicolau Sevcenko, entre outros ainda, mostram bem como as investidas realizadas contra o governo federal ou suas instituições oficiais durante quase toda a década de 1920 exibiram de forma reiterada o equívoco da República, a sua verdade incompleta. Foi assim com os levantes tenentistas de 1922 e 1924 que desembocaram no que seria a mais contundente marcha contra o poder, a Coluna Prestes. Mas também foi o que esteve em jogo na movimentação anarco-sindicalista de fins da década de 1910 e da fundação do Partido Comunista, em 1922. Mesmo as revoltas populares mais espontâneas combatiam a precariedade com que se tratava das questões sociais. Num como noutro interessava a denúncia dos pecados, dos vícios enfim, dos erros dos hinos nostálgicos do passado. Tais movimentos observaram formas de ação, aplicaram regras aos seus militantes, produziram suas verdades e seus princípios, ou melhor converteram seus princípios em verdades.

A mesma historiografia responsável por essa representação do período, que retrocede ao governo Campos Sales e vai até Washington Luiz, é também atenta ao papel desempenhado pela educação pública nas estratégias de reorganização ou contestação do poder.

Boris Fausto situa a instrução na estratégia anarquista de luta contra os aparelhos ideológicos de Estado e da Igreja ${ }^{1}$, Edgard Carone indica o papel

${ }^{1}$ FAUSTO, Boris. Trabalho urbano e conflito social (1890-1920). 4 a edição. São Paulo: Difel, 1977. p. 81 e 82. 
que ela teve no esquema de auto-valorização dos estratos médios da socieda$\mathrm{de}^{2}$. É o mesmo esquema que Maria Lígia Coelho Prado identifica no programa de ação do Partido Democrático ${ }^{3}$. Esses três estudos não assumem o tema da educação como diretamente político, ou diretamente ideológico, deixando-o, pacificamente, entre a ação dos militantes e o contencioso dos intelectuais. É, por outro lado, a obra pedagógica embotada na ação política de contestação do poder levada a efeito por toda década de 1920 que Raymundo Faoro põe entre parênteses no programa reformista das classes dominantes. Na sombra das aspirações culturalmente autonomistas, nota, o governo deveria educar, cultivar e orientar o povo ${ }^{4}$. São ainda essas as sendas trilhadas por Décio Saes e De Decca quando avaliam as exigências que o tema da industrialização fazia aos seus prestigiadores. Tratava-se de uma vasta empresa intelectual da burguesia industrial em busca de instrumentos e processos de ensino capazes de intensificar a racionalização do trabalho ${ }^{5}$.

A educação é vista por parte dessa historiografia como uma instituição constitutiva da identidade social. É o caso, por exemplo, da Escola da Praia Vermelha para os jovens militares e da Escola Nacional de Belas Artes para as pessoas de prestigio do círculo cultural carioca no início do século. As análises de Celso Castro quanto à ação política dos militares na primeira repúbli$\mathrm{ca}^{6}$ e de Angela de Castro Gomes em relação ao modernismo carioca ${ }^{7}$ colocam essas duas instituições num campo de disputas sociais importante. No primeiro caso, a disputa por prestígio social entre os bacharéis militares e civis,

${ }^{2}$ CARONE, Edgard. A Primeira República (1890-1930): texto e contexto. São Paulo: Difel, 1973. p. 298 e 329.

${ }^{3}$ PRADO, Maria Lígia Coelho. A democracia ilustrada: o Partido Democrático de São Paulo, 1926-1934. São Paulo: Ática, 1986. p. 11-12.

${ }^{4}$ FAORO, Raymundo. Os donos do poder: formação do patronato político brasileiro. 10 edição. São Paulo: Globo, 1995. p. 673.

${ }^{5}$ SAES, Décio. Classe média e política na Primeira república brasileira (1889-1930). Petrópolis-RJ: Vozes, 1975. p. 59; DECCA, Edgard de. 1930, o silêncio dos vencidos. São Paulo: Brasiliense, 1981. p. 180.

${ }^{6}$ CASTRO, Celso. Os militares e a República: um estudo sobre cultura e ação política. Rio de Janeiro: Zahar, 1995. p. 52-55.

${ }^{7}$ GOMES, Angela de Castro. Essa gente do Rio...: modernismo e nacionalismo. Rio de Janeiro: Fundação Getúlio Vargas, 1999. p. 29. 
no segundo, a resistência ao "novo" que atacava os paradigmas que lhe conferiam prestígio. Permitem senão vislumbrar, pelo menos considerar as relações tempestuosas que assinalavam o conjunto de estratégias pelas quais diferentes grupos tentavam manter ou melhorar sua posição na estrutura social. Assim considerada, a educação escolar é tomada como produtora de posições diversas e ambíguas, a bem da verdade, mas que, a despeito disso, consolidavam a presença e importância de suas instituições.

Há análises sobre o período que destacam a importância estratégica do tema da educação nas lutas em torno da regulamentação profissional, no debate político ou nos confrontos sociais. São por elas que passam pesquisas tão diversas quanto as que Edmundo Coelho, Leôncio Basbaum e Maria Helena Capelato fizeram acerca da década de 1920. São as reformas da instrução o palco comum no qual se desenvolveram os debates em torno da liberdade profissional, de um programa de reformas sociais, e da luta contra a proletarização crescente produzida pela carestia dos anos 1920 que analisam. O sistema público de instrução, o ensino superior e o modelo de escolarização no combate político pela educação adquirem significação social, com implicações que não foram somente profissionais ou setoriais. Elas acarretaram um protesto que dizia respeito a todos. Criticava-se o projeto de construção da república. As reformas federais da instrução, descritas por Edmundo Coelho, o Inquérito de 1926 sobre o ensino paulista realizado pelo Estado de São Paulo, analisado por Maria Helena Capelato e o fenômeno do bacharelismo, apontado por Leôncio Basbaum, colocaram em movimento, no jogo oligárquico, as condições de exercício profissional ${ }^{8}$, de coesão e ascensão sociais ${ }^{9}$.

Também são conhecidas tanto as análises sobre as condições oferecidas pelo sistema de ensino na consolidação de um campo intelectual quanto as reflexões sobre a posição do intelectuais diante do funcionamento de tal sistema ou, ainda, sobre o seu papel na configuração desse sistema, no país provenientes das pesquisas acerca do modernismo e da modernidade brasileiros. São

\footnotetext{
${ }^{8}$ COELHO, Edmundo Campos. As profissões imperiais: medicina, engenharia e advocacia no Rio de Janeiro, 1822-1930. Rio de Janeiro: Record, 1999. p. 251-255.

${ }^{9}$ BASBAUM, Leôncio. História sincera da república. São Paulo: Alfa-Omega, 1975. p. 196; CAPELATO, Maria Helena. Os arautos do liberalismo: imprensa paulista, 19201945. São Paulo: Brasiliense, 1989. p. 140-149.
} 
as estratégias de reconversão às profissões intelectuais encetadas pelos indivíduos provenientes dos ramos empobrecidos da oligarquia e o ônus político e social da falta de um princípio de identidade que remetesse a vínculos institucionais, isto é a ausência de um campo autônomo com suas hierarquias e estratégias alicerçadas em critérios relativamente estáveis, os postulados que iluminam o desenho e as características dessas pesquisas. Nelas o tema da educação aparece num quadro particularmente interessante de escolarização: constitui a oportunidade de acumular um tipo de capital cultural específico e valoriza$\mathrm{do}^{10}$, participa, como instrumento político, da radicalidade dos embates sobre a laicidade do ensino e nas discussões sobre cultura popular, e, como atividade, em todos os seus níveis, das perspectivas profissionais dos intelectuais ${ }^{11}$, ou, então, repercute na organização dos setores culturais, campo no qual a prática dos intelectuais incide diretamente ${ }^{12}$.

É significativo que o tema da instrução pública apareça em estudos com preocupações tão diversificadas. As questões que esses estudos propõe são bastante preliminares mas não sem importância. Poderiam ser esquematicamente formuladas no seguinte questionário: qual o papel ocupado pelo sistema público de ensino nas relações de poder encenadas na primeira República? De que estratégias o poder público lançou mão para reorganizar a instrução pública da capital federal? Em uma sociedade oligárquica, que tipo de estratégia foi capaz de produzir discursos acerca da educação popular de modo a caracterizá-la e constituí-la como instituição tão necessária? Com essas questões gostaria de pensar os aspectos da trama social e política do país que efetivamente se procurou dar solução com as reformas da instrução pública por toda a década de 1920.

\footnotetext{
${ }^{10}$ MICELI, Sérgio. Intelectuais e classe dirigente no Brasil (1920-1945). São Paulo: Difel, 1979. p. 27.

${ }^{11}$ LAHUERTA, Milton. "Os intelectuais e os anos 1920: moderno, modernista, modernização." In.: LORENZO, Helena carvalho de; COSTA, Wilma Peres da. A década de 1920 e as origens do Brasil moderno. São Paulo: Editora da Unesp, 1997. p. 106-107. ${ }^{12}$ PÉCAULT, Daniel. Os intelectuais e a política no Brasil: entre o povo e a nação. São Paulo: Ática, 1990. p. 33-34; SEVCENKO, Nicolau. Literatura como missão: tensões sociais e criação cultural na Primeira República. São Paulo: Brasiliense, 1983. p. 78-80.
} 


\section{Sistema público de ensino e relações de poder nos últimos anos da Primeira República}

As reformas da instrução pública na década de 1920 estiveram frente a um cenário político em face de intensa transformação. $O$ pacto oligárquico por meio do qual consolidou-se o novo regime passou a sofrer importantes distensões. De certo modo pode-se dizer, com Raymundo Faoro, que a política inaugurada por Campos Sales chegou desacreditada aos governos Arthur Bernardes e Washington Luiz:

"As vacilações, as rivalidades que desagregam a unanimidade em torno de Arthur Bernardez refletem o desequilíbrio dos suportes do envelhecido regime. As dúvidas para a indicação do vice-presidente, ao tempo vistas como a causa do movimento de reação, servem para trazer à tona a impossível conciliação. Ao mesmo tempo na transição, o acordo precário das energias que contestam. Na vacilação da política dos governadores, no desafio aos principados, mesmo se unidos, pulsa a rebeldia das camadas populares e do corpo militar, agora reverdecido depois do ostracismo de dois quadriênios. Paradoxalmente, essa combinação subterrânea há de se voltar contra o poder presidencial, não porque lhe negue a legitimidade de conduzir, comandar e dirigir. A reação renovadora quer um governo superior ao estadualismo, às oligarquias, para mandar e liderar, mas em outro rumo. $\mathrm{O}$ ataque será ao presidente porque agora a peça principal do mecanismo é o presidente - ele não é mau porque existe, mas porque governa contra a corrente desencantada neste angustiado pós-guerra. Depois de 5 de julho de 1922, até que soe a decisão de outubro de 1930, o presidente será a força máxima do aparelho governamental, mas estará em defensiva, assediado por golpes sem identidade, não materializados em reivindicações formuladas. Esta história pertence à outra República, num engano que o calendário antecipou" ${ }^{13}$.

De 1922 a 1930 toda uma série de eventos transformou a República dos Conselheiros. De fato, as hostilidades contra o aparelho governamental cerca-

${ }^{13}$ FAORO, op. cit., p. 619. 
ram-lhe com motins e colunas, com golpes sem identidade. A brutalidade policial não continha a efervescência das tensões sociais e o exército era incapaz de vencer a subversão tenentista. Confinada à função política do seu poder, a presidência da República e, com ela, a ação pública perdeu respaldo social. O aviltamento das condições de manobra das oligarquias governistas foi contrabalançado pela ação de várias organizações civis. A Liga de Defesa Nacional, o Centro D. Vidal, a Associação Brasileira de Educação, o Partido Democrático, a Aliança Nacional Libertadora, a Aliança Liberal e o Integralismo avançaram propostas de reforma do Estado e de políticas sociais. Todas essas organizações ocuparam os espaços que o poder público não dominou com sucesso. O que se passou foi uma certa mutação da prática política. Sob o núcleo monolítico e pretendidamente despolitizado, comprometido somente com uma gestão eficiente e estabilizadora, conseguido com os esforços de neutralização política operados no âmbito da política dos governadores, surgiram entidades interessadas na disputa do monopólio da competência em diversas áreas do governo. Mais que assegurar novas formas de participação na vida social e política das classes médias urbanas, essa movimentação civil, senão estabeleceu, reivindicou procedimentos de melhoramento social. Promoveu a convicção de que a auto-ajuda cooperativa e a ética social agitariam para a reforma do Estado.

Uma das tarefas que as reformas Carneiro Leão e Fernando de Azevedo tomaram para si foi a de fazer ver que, efetivamente, os tempos haviam mudado. A primeira coisa a observar sobre elas é que foram pensadas como um instrumento de reforma social. Recompor o sistema produtivo e delinear um civismo de cunho nacionalista a partir da remodelação do aparelho de ensino da cidade foram duas das principais finalidades anunciadas por essas reformas. É nesse sentido que reivindicavam a modernização das coordenadas sociais, econômicas e culturais conservadas por quase quatro décadas de iniquidade política patrocinadas pelas oligarquias mandatárias. Como política educacional essa preocupação ganhou contornos específicos.

A idéia de comunidade é a primeira especificidade da política educacional desenvolvida por Carneiro Leão, entre 1922 e 1926, e Fernando de Azevedo, entre 1927 e 1930, em relação ao discurso político corrente. É bem verdade que ela foi regida pelo princípio da unidade nacional, carro chefe das discussões políticas do momento, entretanto, nas propostas pedagógicas a idéia de comunidade aparece como um instrumento eficaz de produção da identidade social do indivíduo perante a coletividade nacional. Dessa perspectiva, foi 
menos como ideologia política e mais como condição pertinente ao aprimoramento da democracia representativa que a idéia de comunidade penetrou nos enunciados das reformas da instrução pública durante os anos 1920 na cidade do Rio de Janeiro.

O pressuposto de que a educação adequada à escolarização pública seria aquela que melhor preparasse para a vida produtiva do indivíduo, para o trabalho, foi outra característica particularizada nas preocupações pedagógicas alimentadas pelas reformas Carneiro Leão e Fernando de Azevedo. O intuito era o de despertar ou descobrir uma vocação, de inculcar uma habilidade. $\mathrm{O}$ ensino vocacional e os gabinetes de orientação profissional de certa forma materializavam, em departamentos específicos, a fórmula sob a qual ambas as reformas desejaram equacionar as questões referentes à recomposição do sistema público de ensino da capital federal.

E, finalmente, não se pode esquecer do papel político desempenhado pela escola pública na formação moral e cívica das crianças. Esse foi mais um tópico freqüentemente reiterado nos textos oficiais das reformas da instrução do período. $\mathrm{O}$ fato de que a escola pública servia não apenas para assegurar a autonomia do indivíduo, mas também e, sobretudo, para garantir a integridade geral da sociedade dominou as representações oficiais acerca das finalidades da educação popular. Creio que essas representações revelam o modo como as reformas do ensino procuraram contribuir para a regulamentação da ordem social: conforme as exigências de fundamentação do Estado. Isto é, conservando as formas de relações sociais mais adequadas à essa fundamentação e tornando tal fundamentação um valor reconhecido como valor em si mesmo desejável a despeito de qualquer diferença étnica, religiosa ou social.

Mas não foram somente as referências sociais, econômicas e culturais que ganharam contornos específicos quando tornados parte integrante das políticas de educação pública. A própria disputa política em torno da implementação das reformas da instrução pública merece ser observada nos seus particulares. Dessa perspectiva, a primeira questão que se apresenta é a do tempo de escolaridade. Esse foi o aspecto sobre o qual a discussão acerca das finalidades da educação popular esteve determinada de modo mais preciso. Foi uma discussão em duas frentes. A primeira visava a solução de um problema de natureza cívica e nacional realmente grave, na avaliação de Carneiro Leão. A formação das novas gerações foi o motivo de um desafio intransigente entre duas correntes fortes, lideradas por alguns nomes de muito prestígio e evidência sociais. De um lado, os que queriam a escola primária limitada à alfabetiza- 
ção em quantidade e extensão, de outro, os que desejavam elevá-la a função de elemento educador, aparelhada de recursos maiores e de ação mais prolongada sobre a população. No primeiro caso, a Liga de Defesa Nacional (1916) propugnava a alfabetização do povo. Acreditava ser maior vantagem elevar no máximo o número dos que soubessem ler e, para isso, promovia o ensino de primeiras letras tão sumário quanto possível. No outro, aqueles que entendiam ser o melhor modelo para a escola pública um ensino primário que desse não apenas conhecimentos mais amplos como fosse um seguro início de educação moral no preparo do cidadão capaz de cooperar com o país. Desse grupo não só resultou a Associação Brasileira de Educação (1924) como também diversas administrações da Diretoria Geral de Instrução Pública no Distrito Federal. Os adeptos da Liga costumavam denunciar a dilatada duração dos cursos primários, as exigências de uniforme, os programas pedantescos, enfim, o escárnio à pobreza produzida na escola pública como impedimento à extensão da alfabetização. Já a ABE e mesmo diversos Diretores da Instrução carioca reconheciam na mera alfabetização, desacompanhada da educação, "da verdadeira educação dos sentimentos", um perigo individual e social dos mais graves ${ }^{14}$.

A segunda frente, reuniu posições acerca dos métodos de ensino. Ela foi mais consensual e respondeu pela modificação dos métodos, seu leitmotiv era a otimização dos procedimentos pedagógicos. Ela não dividiu posições, mas preocupações. De um lado, esteve em jogo a capacidade de aumentar a população escolar, pelo emprego do sistema de dois turnos, de outro a eficiência do trabalho escolar, pelo cuidado com as prescrições acerca da duração das lições e das tarefas, a extensão das atividades e o rendimento dos alunos.

À disposição dos "tempos" de aprendizagem seguiu-se a preocupação com sua relação com as condições de vida da população. Entrementes, não só as preocupações com a ação pedagógica ou a formação escolar detiveram a atenção dos reformadores da instrução pública nesse período, as implicações produzidas pelas mudanças dos horários de entrada e saída da escola e, mesmo das condições de deslocamento dos alunos que completavam o ensino primário para os cursos anexos, a Escola Normal ou a uma das escolas profissio-

${ }^{14}$ CARVALHO, Marta Maria Chagas de. Molde nacional e fôrma cívica: história, moral e trabalho no projeto da Associação Brasileira de Educação (1924-1931). São Paulo: USF/FAPESP, 1999. 
nais criou polêmica. As distâncias percorridas pelas crianças para chegar à escola, as formas de transporte utilizadas para tanto e o trabalho exercido pela infância pobre eram percebidos pelas autoridades do ensino e incorporados pelas colunas da imprensa ao universo escolar de preocupações com a educação, já articuladas às exigências por que passavam as populações da periferia urbana para freqüentar a escola.

Outro ponto de disputa diz respeito aos aspectos materiais da escolarização. A infra-estrutura necessária para erradicar o analfabetismo da capital republicana foi o ponto nevrálgico de ambas as reformas da instrução. No esforço de normalização dos valores morais prescritos pelos programas de ensino escolar as reformas da instrução no Rio de Janeiro procuraram configurar as noções de higiene, nação e trabalho e, também, os padrões orais e escritos da cultura letrada por meio do investimento material. As fichas médicas, psicológicas e pedagógicas, as solenidades, os exercícios físicos, as exposições escolares e os trabalhos manuais, nesse sentido, permitiram a circulação tanto de uma escrituração cotidiana das categorias psicológicas solicitadas na aprendizagem quanto dos dispositivos de disciplina do corpo. Uma e outra implicadas com o inventário, a distribuição e os usos dos objetos capazes de conferir um sentido funcional à linguagem, ao juízo e ao gosto burgueses. É dizer que as reformas do ensino público procuraram fazer a criança viver uma identidade ou cultura objetivada, hierarquizada e refundida por processos e recursos implicados com a contextualidade (o prédio escolar, os museus, pinacotecas, fábricas, feiras, jardins e repartições públicas, a biblioteca, o cinema e exposições diversas) ou materialidade (materiais fitológicos, zoológicos ou geológicos, de higiene ou de produção, tabuleiro de areia) da aprendizagem. Tratava-se de reorganizar o próprio espaço da educação. Entre 1922 e 1930, as reformas dos programas de ensino escolares tornaram discurso pedagógico a organização das formas de vida social segundo modelos de representação e de práticas oferecidos à observação por tecnologias materiais. O cinema educativo, o edifício da escola e o estudo da cidade contextualizavam a educação num ambiente de convivência social e materializavam a aprendizagem da criança fazendo-a observar o filme, a arquitetura e a cidade. Pode-se deduzir que os embates em torno da implementação de um tal plano de reforma não se deram em torno do conteúdo mas do orçamento. Enquanto o planejamento das reformas do ensino público foi alvo de um trabalho tecnicamente cuidadoso de reorganização das referências profissionais do professorado 
e de enunciação das "novas" fórmulas pedagógicas, o trabalho político concentrou-se na consolidação de um orçamento suficiente para a reestruturação planejada do sistema escolar público.

Diferente do que se poderia chamar de referências ideológicas das estratégias de ação da Diretoria de Instrução sobre as práticas de ensino utilizadas na escola pública, as negociações em torno do tempo de escolaridade e de infraestrutura do aparelho escolar da capital não se limitaram às iniciativas administrativas, dependeram, sobretudo, da eficiência dessas iniciativas em reorganizar o sistema público de ensino municipal nos seus diferentes níveis: primário, normal e profissional. Parece-me estar aí a tarefa principal das reformas do ensino público da capital federal nesse período: na reestruturação do sistema de educação pública vislumbrou-se um meio de cumprir um amplo programa de reforma social, uma espécie de revolução branca, sem armas.

\section{A reorganização do sistema público de ensino da capital federal}

Por trás dessa tarefa, havia a ambição de poder fazer da escola um espaço de formação profissional e de emancipação social. Para a Diretoria Geral de Instrução do Distrito Federal, as várias aparelhagens que eram os programas de ensino, o regulamento de educação, as instituições de assistência social e os prédios escolares ofereciam os meios de transformação da escola pública. Por meio desses dispositivos, entre 1922 e 1930, a escola pública promoveu uma fórmula de mediação das relações entre a infância, a família, a cultura, a economia e o estado que esteve comprometida com a busca de uma resposta para os problemas de pobreza, diversidade cultural e vida urbana que dificultavam a administração da vida social pelos poderes públicos. As conexões entre escola e ambiente social foram tornadas mais explícitas no discurso público e os educadores que atuaram no Rio de Janeiro aumentaram suas bases populares e apoio político apelando aos interesses da classe média urbana ${ }^{15}$.

\footnotetext{
${ }^{15}$ PERALVA, Angelina Teixeira. Classe Moyenne, luttes sociales et education au Brésil. Tese de doutorado. Paris: Institut D'Etude du Developpement Economique et Social, Universidade de Paris I, 1986. p. 98-220; SAES, Décio. Classe média e política na Primeira república brasileira (1889-1930). Petrópolis-RJ: Vozes, 1975; COSTA, Bolivar. O drama da classe média. Rio de Janeiro: Paz e Terra, 1973. p. 81-90.
} 
As mudanças dos programas escolares, que favoreciam a construção de uma linguagem nacional, de uma ética do trabalho e o desenvolvimento do caráter contavam com a aquiescência dos literati da cidade. $\mathrm{O}$ apelo à filantropia da boa sociedade fizeram-na participar das iniciativas do estado de assistir a infância pobre nas escolas públicas. As perspectivas administrativas regulamentaram padrões de formação das crianças e visibilidade da ordem implicados com a idéia de um serviço social para a comunidade.

Em contrapartida, a redefinição dos vínculos da escola com o poder público envolveu o estabelecimento de dispositivos capazes de operacionalizar o esforço de sistematização da educação popular. O planejamento, a avaliação e o desenvolvimento dessa tarefa coletiva e cheia de propósitos requisitou novas soluções de escolarização. Entre 1922 e 1930, elas foram se sucedendo no discurso da Diretoria Geral de Instrução Pública. Primeiro, um novo método de ensino-aprendizagem daria ênfase aos meios ativos de educação. Em seguida, os programas de assistência social e de controle sanitário incorporados aos processos de escolarização fariam do melhoramento social também uma tarefa escolar. Depois, haveria um conjunto de tensões culturais que se procuraria resolver mediante a escola. Ainda teriam lugar nos discursos do departamento de instrução interesses sobre o ensino profissional e a organização do trabalho livre desde os bancos escolares. Finalmente, através do aproveitamento de saberes, de técnicas e de recursos associados a ação governamental, os métodos ativos de educação seriam enunciados como um conhecimento especializado em prol do avanço da sociedade.

A pedagogia centrada na criança alterou as fórmulas de escolarização do poder público no Distrito Federal. Inicialmente, foi veiculada como um método de observação direta da realidade. Sem procurar escrever metodologia, Carneiro Leão orientou-a para a fixação da realidade como motivo de cultura e para a observação e a ação como métodos de trabalho ${ }^{16}$. Já sob Fernando de Azevedo os programas escolares organizavam a matéria a ensinar em torno de três ou quatro grandes centros de interesse na mesma medida em que enfatizavam a atividade e o trabalho individual e coletivo dos alunos. O ensino precisava de

${ }^{16}$ CARNEIRO LEÃO, Antônio. Planejar e agir. Rio de Janeiro: Jornal do Commercio, 1942. p. 74-75. 
um tempo flexível de realização, que se ajustasse às necessidades e aos interesses psicológicos dos alunos. A partir de 1929 os programas de ensino das escolas primárias propunham experiências com os conceitos, excursões e a atividade conjunta de professor e alunos. O ensino público, nesse momento, estava aberto à vida prática, isto é, às tarefas de elaboração e pesquisa dos próprios alunos. Em contrapartida, solicitou técnicas, instituições e instrumentos capazes de manter a ordem, assim como inculcar a disciplina, na plenitude de uma experiência concreta e vivida.

A incorporação de demandas sociais nos processos de educação das crianças se deu paralelamente à organização das ciências sociais como disciplina. Foi uma época de numerosos lançamentos de obras de sociologia. Só nos primeiros anos da década de 1920 foram publicados uma série inteira de livros: O povo brasileiro e sua evolução (1922), Populações Meridionaes do Brasil (1922) e Pequenos estudos de psycologia social (1923), de Oliveira Vianna, A questão social (1922), de Antônio de Sampaio Dória, Brasil e a raça (1928) e A formação espiritual do Brasil (1930), de Antônio Batista Pereira, Princípios de sociologia jurídica (1922), de Eusébio de Queirós Lima, Retrato do Brasil (1928), de Paulo Prado e O Brazil na América (1929), de Manoel Bomfim. Também foi um período de intensa atividade em torno das ambições e desejos de melhoramento social. Em 1923 a fundação da Liga Brasileira de Higiene Mental, em 1924 a organização da Associação Brasileira de Educação, em 1929 a criação da Federação Nacional das Sociedades de Educação e mesmo toda a movimentação partidária que ia da fundação do Partido Comunista em 1922 e do Partido Democrático do Distrito Federal em 1927 representaram manifestações relevantes e autênticas de um esforço de aperfeiçoamento social. Ainda funcionavam na capital federal o Instituto de Proteção à Infância, a sede da Cruz Vermelha do Brasil e os institutos Manguinhos e Benjamin Constant. Toda essa movimentação envolveu a escola pública. Os discursos de Carneiro Leão e Fernando de Azevedo traziam-lhe o compromisso com a melhoria das condições de vida e a eliminação da miséria ${ }^{17}$. As fichas de saúde eram vistas como um meio de identificar as fontes de males

${ }^{17}$ AZEVEDO, Fernando de. Novos caminhos e novos fins: a nova política de educação no Brasil. São Paulo: Melhoramentos, 1931. p. 165; CARNEIRO LEÃO, Antônio. op. cit. p. $99-102$. 
sociais como a pobreza e as doenças. A ênfase dos programas escolares na educação sanitária e na higiene foi considerada uma abordagem que poderia determinar uma ação eficaz de melhoramento social. Entre 1922 e 1929 a educação pública foi associada a um conjunto de práticas e convicções sociais que surgidas dentro de um segmento das classes médias urbanas alcançaria as classes populares mediante a sua escolarização.

A extensão que se pretendia dar ao processo de escolarização tinha base em prescrições tanto sociais quanto morais. O esvaziamento do conflito social no ambiente escolar foi evidente na linguagem e no tom dos textos manuseados pelo magistério. Em contrapartida, indicavam que os alunos de qualquer escola pública eram suscetíveis aos mesmos padrões de conduta e aprendizagem. Por isso, o controle solicitado às professoras visava àqueles indivíduos e grupo que divergiam da norma. O esforço para fazer da instrução pública uma organização específica de relações sociais dissociadas de conflitos de classe ajudou na formulação de uma estrutura educacional que ampliava as estratégias e as práticas de controle e disciplina das crianças para além dos resultados escolares. Interessavam também os mecanismos de permanência e a qualidade da freqüência dessas crianças. Manter sob o domínio público a formação moral, intelectual e física das crianças das classes populares foi um dos objetivos desse esforço. Carneiro Leão e Fernando de Azevedo relacionaram a organização da sociedade com o indivíduo e a família para proporem reformas no aparelho de ensino público ${ }^{18}$. Paralelamente, desenvolveram e implementaram ações que permitiam testemunhar os efeitos das atitudes individuais sobre a comunidade, posicionando-os como questões de governo. As práticas de trabalho em comunidade, os instrumentos de controle, inspeção e educação sanitária, os jogos e os métodos ativos de aprendizagem criavam condições de avaliar as capacidades pessoais que levariam a uma adaptação bem sucedida do indivíduo ao seu meio. Não obstante essas ações, relações, formulações e indicações conterem os valores de um projeto liberal de educação também impunham categorias, distinções e diferenças determinadas por uma moralidade postulada no âmbito dos deveres do cidadão, conforme o entendi-

${ }^{18}$ CARNEIRO LEÃO, Antônio. O ensino na capital do Brasil. Rio de janeiro: Typ. do Jornal do Commercio, 1926. p. 127; AZEVEDO, Fernando de. "A socialização da escola." Boletim de Educação Pública. Ano I, n. ${ }^{\circ}$ 2, Rio de Janeiro, julho - setembro de 1930. p. 133. 
mento de Rui Beisiegel das conexões entre mudança social e mudança educacional construídas no Brasil ${ }^{19}$.

A Diretoria Geral de Instrução Pública do Distrito Federal tomou o ensino profissional como instrumento de educação técnica e, também, social da população pobre. De fato, entre as finalidades que o Decreto $n .^{\circ} 2.940$ previu para o ensino técnico profissional constavam a elevação do "nível moral e intelectual do operariado" e o desenvolvimento, nesses trabalhadores, da "consciência das bases científicas e da significação social de sua arte" ${ }^{20}$. Se existiu, nos primeiros anos da década de 1920, muita preocupação com a orientação profissional dos alunos ainda no ensino primário, em 1928, havia também o esforço de aliar à aprendizagem de um ofício uma preparação escolar de prestígio cultural. As soluções encontradas para conjugar termos sociais e morais ao discurso da formação técnico-profissional repercutiram representações sobre as condições de mudança social das famílias de trabalhadores. De modo que os métodos propostos e a organização conseguida para as escolas e institutos profissionais do Distrito Federal buscavam no culto da "ascensão individual", do "emprego" e da "independência econômica" promover o interesse dessa parcela da população. O debate que se seguiu mostrou-os a mercê de uma especialização que já se refletia em cada passo da produção industrial. As idiossincrasias entre as possibilidades técnicas de operações produtivas específicas e as preocupações didáticas com o trabalho humano restringiu, por um lado, a Escola Álvaro Baptista ao ensino de artes gráficas, a Escola Visconde de Cayrú ao ensino de marcenaria e obras em madeira, o Instituto João Alfredo ao ensino de eletro-técnica e mecânica e a Escola Amaro Cavalcanti ao ensino comercial. De outra parte, a defesa senão de uma imitação da realidade social da produção industrial, da necessidade das escolas profissionais corresponderem a essa realidade com uma produção capaz de concorrer nos mercados com a indústria armou de argumentos a reivindicação da faculdade das oficinas das Escolas e Institutos Profissionais aceitarem encomendas relativas a sua especialidade. Esta efervescência curricular acerca da formação técnica, moral e intelectual do operariado, apesar de excluir algumas perspectivas sociais da profissionalização, procurou favorecer aqueles que se destina-

\footnotetext{
${ }^{19}$ BEISIEGEL, Celso de Rui. Estado e educação popular. São Paulo: Pioneira, 1974. p. 27-59.

${ }^{20}$ DISTRITO FEDERAL. Decreto n. ${ }^{o}$ 3281, de 22 de janeiro de 1928. Art. 269, alínea b e c.
} 
vam ao trabalho manual apelando diretamente para interesses de "uma sociedade baseada na organização do trabalho e da indústria"21.

Face a rede de instituições que se projetou sobre a escola pública surgiram padrões específicos de organização dos serviços de educação do Distrito Federal. A pedagogia centrada na criança, a incorporação de demandas sociais nos processos de educação e as prescrições morais indicadas para a instrução de massa tiveram consequiências imediatas nas práticas diárias da escola. Os serviços de assistência e prevenção médica, a educação física, os meios utilizados para proporcionar meios planejados para governar a espontaneidade infantil e encorajar a solidariedade e a bondade entre as crianças apareceram como uma expressão das mudanças que naquele momento a Diretoria Geral de Instrução Pública procurou provocar no conhecimento que organizava as práticas de sala de aula e ensino. E, de certa forma, serviram de apoio para uma arquitetura de vínculos entre as rotinas da escola e as práticas sociais e econômicas úteis para uma sociedade que enfrentava a industrialização, a urbanização e a "assimilação" de populações de imigrantes, de emigrantes e de marginalizados.

A vaga reformista que na década de 1920 alterou as fórmulas de escolarização no Distrito Federal procedeu de operações, usos e conexões institucionais conseguidas em negociações hábeis, ou ardilosas. Alguma evidencia mostra sua ênfase na construção de enunciados, de dispositivos, de instrumentos e de tecnologias para controlar as funções de ensino das escolas públicas durante a realização das reformas na estrutura de escolarização da capital. O que supõe o reconhecimento das diversas operações de construção do sentido de instrução pública efetivadas pelas reformas que Antônio Carneiro Leão e Fernando de Azevedo comandaram entre 1922 e 1930. Mas não se pode compreender inteiramente o empreendimento somente pela sua pertinência operatória. Também os agenciamentos sociais, os aparelhos de Estado e a ideologia que a configura e as redes de práticas que organizou-a histórica e socialmente são indícios de uma eficácia política. Do mesmo modo, as técnicas e as estratégias pelas quais se fizeram engendrar nos planos de educação das escolas públicas da capital deixaram vestígios nas reformas do ensino de 1922 a 1930.

${ }^{21}$ AZEVEDO, Fernando de. Novos caminhos e novos fins: a nova política de educação no Brasil. op. cit., p. 47; MENDONÇA, Edgard Süssekind de. A produção industrial nas escola profissionaes. In.: Boletim de Educação Pública, ano I, n. ${ }^{\circ}$ 2, p. 222-238, abr./ jun. 1930. p. 225. 


\section{Instrução pública e educação popular}

Um princípio geral no que diz respeito ao entendimento das práticas, dos instrumentos e dos dispositivos postos em funcionamento durante as reformas do ensino público na década de 1920: parece-me que a movimentação social de fins da década de 1910 e na reorganização política da década de 1920 concretizadas na organização do Partido Comunista, do Bloco Operário Camponês e do Partido Democrático tornou manifesta a violação das convicções intelectuais daqueles que governavam. Ao mesmo tempo foi o apogeu da penetração de intelectuais no governo. Acusada de não cumprir as suas promessas, de trair seus sonhos, a República recolheu aos seus gabinetes, confortáveis e bem mobiliados, os intelectuais dispostos em acomodá-la numa autoridade planificadora sem fazer vacilar a ordem social vigente. Neles repousou a ansiedade nascida da ausência de instrução da população, largada à mingua nas fronteiras da ordem e da moralidade. E, também, a convicção de que só a educação do povo seria capaz de dissipar os devaneios da fantasia republicana, aquela que proclamou a igualdade de todos perante a lei, mas ao mesmo tempo apunhalou-a em nome dos privilégios particulares, dos favores políticos e do racismo científico; declarou a democracia sagrada, mas submeteu-a aos constrangimentos das oligarquias agrárias e, ainda, afirmou a soberania das leis, enquanto era governada por despóticos Presidentes ou por estranhas entidades assemelhadas. Essa convicção apoiou bem as pretensões desses intelectuais a um papel destacado no processo de acusação da República, mas sobretudo, nos procedimentos de consagração de novos padrões de verdade, beleza e bondade.

É preciso não esquecer que essa convicção foi o grande fenômeno em torno e a partir de que pensou-se a reestruturação do ensino público no Rio de Janeiro. Ao menos é essa a interpretação que Jorge Nagle dá às discussões sobre a educação pública quando analisa o modelo de escolarização articulado nas reformas do ensino durante a década de 1920. Indica como seu responsável uma nova categoria profissional, o técnico em educação: "Este é que vai daí por diante tratar com quase exclusividade dos assuntos educacionais. (...) Analisados pelos técnicos os problemas [de educação] se comprimem num domínio especializado, e se segregam, ao serem menosprezados as vinculações com os problemas de outra ordem"22.

\footnotetext{
${ }^{22}$ NAGLE, Jorge. Educação e sociedade na Primeira República. São Paulo: EPU; Rio de Janeiro: Fundação Nacional do Material Escolar, 1974. p. 102.
} 
Os limites, entretanto, que Jorge Nagle confere a análise dos problemas educacionais dificultam o entendimento do significado político da ação reformista impingida ao sistema público de ensino. Para ele, as reformas da instrução pública realizam-se na mesma medida em que conseguiam organizar o ensino público de acordo com um método de gestão administrativa baseada no conhecimento científico do meio, com largas perspectivas sociais e aberta para as idéias amplamente renovadoras que, segundo seu entendimento, sopravam de todas as direções. Foi Marta Carvalho quem notou o quanto semelhante é essa análise da interpretação dada às reformas do Distrito Federal e Minas Gerais por Fernando de Azevedo na A Cultura Brasileira.

É justamente com os limites da interpretação de Jorge Nagle que Marta Carvalho opera sua crítica ao projeto político embotado nos programas de reforma da educação pública durante a década de 1920. Ela compreende o movimento de remodelação do ensino público a partir de suas cores políticas. Ao contrário de Nagle, que acreditava terem as reformas do ensino público do período transformado um programa mais amplo de ação social num restrito programa de formação na qual a escolarização era concebida como a mais eficaz alavanca da história brasileira, diz ela se tratar de uma resposta política: "uma das respostas políticas ensaiadas por setores da intelectualidade brasileira na redefinição dos dispositivos de dominação vigentes" ${ }^{\text {"23 }}$.

Trinta anos depois de instalada, a República era vista como uma vítima das relações históricas, uma nova espécie de Argus burocrático: ao invés de ver, era visto, e com maus olhos. Buscava-se uma nova realidade, uma transformação da consciência nacional, na verdade, uma consciência nacional. O desejo do novo trouxe consigo o desejo de fazer tábula rasa do passado, cuja definição política Zygmunt Bauman encontrou junto a idéia de Estado cultivada pelas classes instruídas de fins do século XIX: "Como o ideal que buscavam, o Estado das classes instruídas pertencia ao futuro. Isso o tornava mais ainda um local de liberdade, não estorvado por experiência solene de prática política; a necessidade, por assim dizer, devia ser vislumbrada apenas junto com a irrevogável certeza do passado" 24 .

\footnotetext{
${ }^{23}$ CARVALHO, Marta Maria Chagas de. "Notas para reavaliação do movimento educacional brasileiro (1920-1930). Cadernos de Pesquisa. São Paulo (66): 4-11, agosto de 1988. p. 7.

${ }^{24}$ BAUMAN, Zygmunt. Modernidade e ambivalência. Rio de Janeiro: Jorge Zahar, 1999. p. 46.
} 
Predizer o futuro foi muito do que fizeram os intelectuais envolvidos nas reformas da instrução pública no Distrito Federal durante a década de 1920. E isso nos dois sentidos apontados por Bauman, o do ideal e o da política. Dessa perspectiva, a obra de Vicente Lícinio Cardoso, subdiretor técnico da reforma Fernando de Azevedo e um dos maiores expoentes da campanha em prol da educação popular durante a década de 1920, revelava muito do sentido tomado pelas reformas da instrução pública quando dizia:

"Instruir é formar cidadãos, é sanear mentalmente, é fundamentar os laços da coletividade dentro da unidade da Pátria. República só pode ser concebida como forma de governo de uma organização vitalmente democrática. Democracia pressupõe instrução difundida e dilatada. Instruir é pois democratizar o homem e republicanizar as instituições políticas. Num meio inculto instruir é de fato governar sabiamente"25.

Da política exigiu-se um compromisso com a Nação. Carneiro Leão ao encerrar o relatório sobre a administração do ensino municipal em 1925 não hesita na afirmação:

"É, portanto, nosso dever procurar todos os meios, fazer todos os sacrifícios, cortar em toda parte, para não comprometermos o futuro das crianças de hoje, daqueles que dependem exclusivamente de nós. A Nação de amanhã, feita por eles, a de ser menos a obra deles próprios, do seu valor intrínseco, do que da capacidade e das possibilidades que lhes dermos para a realizarem"26.

O que se pergunta agora é justamente sobre os meios, os sacrifícios e os projetos que deveriam constituir as reformas da instrução articuladas para realizar a utopia da educação popular, para assegurar o progresso da "Nação de amanhã". Mas, antecipadamente, deve-se sublinhar que a abordagem dessa questão far-se-á nos limites dos textos oficiais, das iniciativas usuais enceta-

\footnotetext{
${ }^{25}$ CARDOSO, Vicente Lícinio. “À margem da república.” In.: CARDOSO, Vicente Lícinio et. al. À margem da história da república. $2^{\text {a }}$ edição, 2 volumes, Brasília: Editora Universidade de Brasília, 1981. (Biblioteca do pensamento político republicano, 8). p. 109. ${ }^{26}$ CARNEIRO LEÃO, Antônio. O ensino na capital do Brasil. op. cit., p. 214.
} 
das pelas reformas Carneiro Leão e Fernando de Azevedo. Portanto, trata-se menos de uma discussão acerca das disputas políticas em torno da educação popular que de uma reflexão sobre a arquitetura do poder construída para controlar os negócios da instrução pública.

Assim, procurarei tomar como ponto de partida para esta reflexão os dispositivos utilizados pela Diretoria Geral de Instrução Pública para condicionar o funcionamento da instituição escolar. Meu itinerário será: a atualização das referências teóricas da pedagogia, a modificação dos programas escolares, a legislação do ensino, a organização de amplos serviços de assistência social e medicina e a construção de novos edifícios escolares.

A atualização das referências teóricas da pedagogia ensinada nas Escolas Normais e das práticas escolares utilizadas no sistema de ensino público empreendida tanto por Carneiro Leão quanto por Fernando de Azevedo conduziu a um novo quadro de referências para o exercício profissional da docência: Kershensteiner, Dewey, Montessori, Decroly, Ferrière entre outros passaram a constituir o referendo técnico-científico da pedagogia no interior da Diretoria de Instrução Pública. Sob ele o poder público pode assumir a educação popular, nos seus diversos níveis, sob o regime da gratuidade e do acesso livre e universal sem grandes justificativas políticas: o compromisso técnico-pedagógico pareceu suficiente para a organização de uma administração voltada à aparelhagem, organização e instalação de um sistema público de ensino capaz de receber, instruir e educar a população sem negligenciar o controle disciplinar, a orientação profissional, a formação cívica, a avaliação e correção física, moral e intelectual dos indivíduos.

A modificação dos programas escolares nos diversos níveis do ensino municipal, de certa forma, oficializou e divulgou esse novo quadro de referências pedagógicas e de questões educacionais. Ela alterou o sentido da formação do professorado, recolocou a Escola Normal em evidência e permitiu investir num tipo paralelo de formação. Os cursos e conferências patrocinadas pela Diretoria de Instrução Pública entre 1923 e 1930 fizeram das novas determinações oficiais conteúdo de um programa de formação que a um só tempo funcionou como oportunidade de aperfeiçoamento didático e de propaganda do regime de idéias que se pretendia implantar com a reforma da instrução pública. Foram os expedientes mais bem sucedidos tanto da reforma Carneiro Leão quanto da reforma Fernando de Azevedo: muito freqüentados pelo professorado e bastante noticiados pela imprensa representaram uma importante ponte entre os novos programas de ensino e os profissionais respon- 
sáveis pela sua aplicação. Foi desse diálogo que as duas reformas tiraram seus maiores dividendos históricos, a criação de uma nova condição, ou melhor, posição política para a educação pública: a profissional.

A promulgação de uma nova legislação de ensino para a capital foi o alvo primeiro das reformas Carneiro Leão e Fernando de Azevedo. A precisão do tiro seria a maior distinção entre elas. Carneiro Leão administrou o ensino sob a jurisdição dos decretos de 1914 e 1916 e mais um conjunto extenso de dispositivos, emendas e regulamentações aprovadas pelo Conselho Municipal ou pelo Senado que tornavam a legislação sobre o ensino municipal um labirinto de regras e disposições. Com a aprovação do Decreto n. ${ }^{\circ} 3.281$ em 23 de janeiro de 1928 foi a própria articulação administrativa que mudou com a legislação. A organização de duas subdiretorias, a criação do almoxarifado privativo da Instrução Pública, a regulamentação para a construção de novos edifícios escolares, e a instituição de concurso público para provisão dos cargos reformularam, antes que o aparelho escolar do Distrito Federal, o funcionamento da própria Diretoria de Instrução. Afetaram substancialmente as circunstâncias nas quais eram feitas as solicitações dessa repartição da prefeitura. Sob o novo código a Diretoria de Instrução Pública abriu concorrência e julgou os projetos de construção dos novos edifícios escolares, tarefa da Diretoria de Obras Públicas, nomeou um chefe para a inspeção médica e inaugurou uma clínica escolar, assumindo atribuições comumente delegadas à Diretoria Geral de Saúde Pública, exigiu qualificações específicas para a direção das escolas profissionais, enfim, centralizou o controle, fiscalização e administração do sistema público de ensino nos limites institucionais de uma equipe de intelectuais, professores, inspetores identificados por um projeto comum de reforma do aparelho escolar: tornar o sistema público de ensino uma instância do poder público na reformulação do sistema produtivo, na formação de uma identidade nacional e na conformação moral dos hábitos e condutas da criança carioca e brasileira.

A organização de amplos serviços de assistência social e medicina preventiva fez parte das políticas de educação de Carneiro Leão e Fernando de Azevedo. Ela teve uma dupla finalidade: social e moral. A um só tempo esses serviços fomentaram tanto uma política de ação social, quanto uma estratégia de moralização das classes populares. Assim, foram criados ou aperfeiçoados serviços que se ocuparam de questões sociais tais como desnutrição, anemia, deficiências visuais, verminoses, a tuberculose entre outras moléstias. A organização dos "pratos de sopa" e dos "copos de leite" nas escolas públicas indicava uma das direções que tomou a reforma Carneiro Leão na sua insis- 
tente tentativa de prolongar a permanência das crianças pobres no sistema de ensino: a distribuição regular de alimentos no intervalo dos períodos letivos. Foi um caminho que Fernando de Azevedo não desprezou. Mas em 1928 a intensidade que atingiu os números da inspeção médico-escolar é que parece dar o tom da reforma Fernando de Azevedo no que tangia seu interesse pela extensão dos anos de escolaridade da população carioca. Na saúde dos escolares a reforma Fernando de Azevedo focalizou os deveres do indivíduo com o Estado. Tudo se daria como num investimento de longo prazo:

\begin{abstract}
"Cada aluno deve na ordem das coisas, transformar-se à sua hora, num fator de produção: sua vida é por assim dizer hipotecada ao Estado, isto é, à comunidade socialmente organizada de que a família é parte integrante. Se morre ou se torna inútil pela moléstia, a sociedade com a qual contraiu uma dívida, no período de educação, sofre uma perda irreparável com a morte ou grave com a redução do rendimento do seu trabalho, com que aumenta, na proporção de sua eficiência e duração, a riqueza econômica e social do Estado"27.
\end{abstract}

Foi, entretanto, na capilaridade dessas relações que tais iniciativas revelavam com maior clareza seu aspecto disciplinar. Eram com as enfermeiras escolares, com os pelotões de saúde, com as professoras e com o programa de higiene que a Diretoria de Instrução Pública tratou dos aspectos morais dos serviços de assistência e prevenção médica. Foram nesses capilares que se procurou inculcar nos alunos as normas de limpeza e higiene de modo que este agisse como um pequeno higienista encarregado de propagar em casa os preceitos aprendidos na escola. Com as professoras e os programas era o suficiente. Com as enfermeiras escolares e os pelotões de saúde era ainda um passo a mais que se procurou dar:

"penetrar no meio social, de que o aluno proveio, no seio de suas famílias, não somente para difundirem, nas camadas populares, a educação higiênica e a profilaxia das moléstias transmissíveis, como também para observarem e conhecerem o estado social e sanitário das famílias"28.

\footnotetext{
${ }^{27}$ AZEVEDO, Fernando de. A reforma do ensino no Districto Federal: discursos e entrevistas. São Paulo: Melhoramentos, 1929. p. 47-48.

${ }^{28}$ AZEVEDO, Fernando de. A socialização da escola. op. cit., p. 179.
} 
Da construção de novos edifícios escolares dependeu a difusão do ensino público na capital. Ao menos foi esse o leitmotiv dos artigos de jornal, das matérias de revistas e das palestras que especulavam sobre o tema. Dessa perspectiva, os resultados que Carneiro Leão obteve com o remanejamento dos professores dá um boa idéia da extensão do sistema público de ensino da cidade do Rio de Janeiro no ano de 1926:

"Para uma área de 43.142 metros quadrados, tivemos o ano passado uma matrícula de 68.012 alunos e uma frequiência média de 52.735 . Este ano a freqüência já atingiu a 53.831. Dando-se um metro quadrado para cada criança não poderíamos ter mais de 43.142 alunos freqüentes, e se conseguimos, premidos pela necessidade, $52.735 \mathrm{em}$ 1925 e 53.831, no ano corrente, já ultrapassamos de muitos milhares de crianças o limite estabelecido pelas determinações pedagógicas. (...)

"Com dois mil professores para reger classes e área de 43.142 metros quadrados é impraticável qualquer modificação para melhor" ${ }^{29}$.

O implemento obtido por Fernando de Azevedo nessa questão foi, numericamente pouco substantivo, não chegaram a somar uma dezena de novos edifícios, mas simbolicamente bastante significativo: o estilo adotado, o neocolonial, era a reafirmação dos valores ditos tradicionais da vida brasileira ao mesmo tempo que cumpria a função de criar a imagem de ruptura das práticas educativas passadas, sendo, como aponta Diana Gonçalves Vidal, o portador do signo da renovação ${ }^{30}$.

\section{Entre o estado de sítio e a revolução, um caminho para a regeneração:}

A presença da escola pública na trama social e política da capital do país cresceu em importância entre 1922 e 1930. A atenção que lhe prestaram as reformas da instrução pública nesse período conviveu e manteve relações com a perspectiva de controlar cientificamente a estirpe humana nacional. Efeti-

${ }^{29}$ CARNEIRO LEÃO, Antônio. O ensino na capital do Brasil, op.cit., p. 34-35.

${ }^{30}$ VIDAL, Diana Gonçalves. "Nacionalismo e tradição na prática discursiva de Fernando de Azevedo." Revista do Instituto de Estudos Brasileiros, n. ${ }^{\circ}$ 37, São Paulo, p. 35-52, 1994. p. 42. 
vamente, por meio da escola pública se pretendeu significar toda uma tecnologia de reforma social. Senão sob a condição de que fosse transformadora do indivíduo, os instrumentos que lhe foram dados fazia entender a maquinaria médica e disciplinar que circundava a sociedade. Fichas sanitárias, edifícios, regulamentos, programas e rotinas faziam aparecer também na escola pública o que era pertinente para a política. De modo que pode-se perfeitamente estudar as reformas da instrução como efeitos de uma aposta dos poderes públicos na regeneração da raça e da nação, do controle policial da população e da instrumentalização do Estado para essas ações. O problema então será levantar a quantia da aposta, verificar a relevância da ladainha de conceitos utilizada direta ou indiretamente para aproximar a instrução pública do poder de Estado.

Portanto, a reorganização dos métodos escolares, a educação sanitária, a nova política de edificações escolares, o regulamento de educação e as instituições de assistência social não só constituíra um quadro de referências escolares. Responderam, sobretudo, às condições de habitação, saúde e trabalho da população pobre do Distrito Federal. O esforço de adequação dos programas e da estrutura escolares em muitos aspectos partilhou mais que preocupações, funções que não eram difíceis de localizar também em áreas como o direito, a medicina e a engenharia.

No início da década de 1920 os bairros miseráveis do perímetro urbano do Rio de Janeiro não pareciam alarmar os bacharéis da República. Ao contrário, indicavam-nos a própria evolução do crescimento da cidade e o alargamento concomitante aos seus progressos. Portanto, não havia porque estranhar as habitações nas favelas ou nos morros: "característica bem evidente da moderna economia capitalista" ${ }^{31}$. Mesmo porque os poderes públicos dispunham de um antídoto singular para corrigir tal efeito: o carmatello e o alvião do progresso que tal como no Morro do Castelo ou do Senado transformariam a precariedade humana em ordem urbana. Entretanto, a instalação de novas favelas no próprio coração da magnifica urbs saneada fez com que o cenário apologético das políticas urbanas empreendidas pela prefeitura carioca renovasse seu vínculo histórico com o círculo monstruoso do processo de regeneração.

A aventura protagonizada por Pereira Passos e Oswaldo Cruz no Rio de Janeiro da primeira década do século XX ainda dizia muito para as gerações

${ }^{31}$ CASTRO, P. J. "Urbanismo". Jornal do Brasil, Rio de Janeiro, 10 dez. 1926. p. 2. 
administrativas da década de 20. Dizia-lhes o que era uma cidade cívica, espaço de sociabilidade e convivência. Informava a respeito das articulações entre a "norma" e a "infração" na construção do espaço urbano. Representava, sobretudo, a ortodoxia moderna do planejamento, da ordem e da beleza. Era pois, ainda na década de 20, uma forma de olhar a expansão urbana. Expansão que deixava de vincular-se ao "antigo" regime patriarcal do estatuto da terra e da produção agrária na medida em que atualizava, em escala industrial, a segregação social de quatro séculos de escravidão entre proprietários e não proprietários, brancos e negros e, ricos e pobres, à ordem competitiva de um Rio de Janeiro inchado de capitalismo. Não se tratava, portanto, de extirpar o atraso rural como o quiseram Pereira Passos e Oswaldo Cruz com a remodelação compulsória ou a vacinação obrigatória, mas de ordenar o progresso modernista como o quiseram Mello Mattos, Alfred Agache e Fernando de Azevedo com o código de menores (1927), o planejamento da cidade (1928) e a reforma do ensino (1928). A mudança de outrora da população pobre para os morros e várzeas do Rio de Janeiro cederia lugar ao saneamento moral de uma cidade que não podia mais prescindir dessa massa de trabalhadores. Medida curativa que a um só momento significava regulamentação, planejamento e reforma. A profilaxia do anormal, do estigma ou do patológico consignada na imagem do saneamento condensou no esforço de regeneração do indivíduo os valores sociais segundo os quais se montou tanto os dispositivos de controle e poder do Estado frente a população quanto os projetos de "modernização" da legislação, da cidade e da cultura.

Sob a rubrica da regeneração da raça e da nação os homens do governo republicano sistematizaram com habilidade política e "competência" técnica um emaranhado de valores morais sobre a sexualidade, a reprodução e a morte num quadro nosológico de doenças e disfunções da psique e da hereditariedade apontadas como responsáveis pelo desequilíbrio e pela decadência do homem civilizado $^{32}$. Não obstante, o "sucesso" crescente da autoridade científica levou-os a crença da possibilidade efetiva de completar pela mão do homem aquilo que a natureza não conseguia alcançar: a civilidade. Tanto o esforço para construir na escola uma psicologia do normal, do adaptativo e do organi-

${ }^{32}$ FONTENELLE, J. P. Compendio de hygiene. $4^{\mathrm{a}}$ edição. Rio de Janeiro: Canton \& Reile, 1932. p. 602. 
zado quanto o pretexto higienista para todo o tipo de limpeza social e a sinistra ambição de uma ciência da hereditariedade vertida em perspectiva de controle da estirpe humana por meio da educação o demonstraram com fartura durante toda a década de 1920. A medicina legal, os higienistas, os testes de inteligência e os esforços para o robustecimento da raça da Sociedade de Medicina e Cirurgia, da Sociedade Eugênica ou da Liga de Higiene Mental não representaram outra coisa que formas de intervir no meio social para produzir, ou assegurar, a normalidade, o progresso e a civilidade da vida coletiva. Assim, o casamento, os cuidados de si, a freqüência escolar, os tratamentos de saúde, os hábitos ou costumes culturais ou morais passavam a ser alvo de políticas ou campanhas públicas de regulamentação ou controle. Elas permearam as reformas da Instrução do Direito Penal e da Saúde Pública na tentativa de disciplinar o marco zero dessas recorrências: o indivíduo. E permaneceram como o aspecto mais saliente de suas propostas coletivas.

O governo republicano absorveu por inteiro a urgência da regeneração. Fez das manifestações sociais caso de polícia, generalizou o controle social no combate de epidemias e endemias, tornou o analfabetismo cancro social. Entretanto, lançou os casos, os combates e os cancros num palco político esvaziado pelo pacto oligárquico, casou-os com a sensação de atraso histórico e, como se não bastasse, vislumbrou-os junto com a irrevogável certeza do passado, colonial, rural e escravocrata. Mesmo assim e diferentemente do início do século, quando sanear e remodelar significava remover o entulho para limpar o terreno de construção de uma ordem civilizada, durante toda a década de 1920 procurou produzir meios artificiais de homogeneização da cultura e da raça no trabalho de construção de um Estado-nação moderno. Tratava-se de discriminar, na cidade, na legislação ou na escola, por meio de regulações restritivas, a dimensão propriamente humana da cultura, ou por meio do endosso irrestrito das práticas científicas, as ambições normativas e planificadoras da política republicana. De um lado alicerçava no domínio público o desejo de "arrancar do Rio de Janeiro a mancha negra que da capital brasileira fazia uma triste continuação da costa d'África" 33 por outro sancionava ao comportamento moral a exprobração ao "não pode, da rebeldia popular à disciplina das ${ }^{33}$ LINS, Sinval A. "A febre amarella através de um seculo de observação clinica e orienta-
ção scientifica". O Brasil Medico. Ano XLIV, n. ${ }^{\circ}$ 10, Rio de Janeiro, 8 mar. 1930. p. 280. 
ruas", à "anarquia impenitente armada à dinamite contra o governo legítimo", à "recusa do alistamento eleitoral", à "falsificação da estatística ou do recenseamento", à "escusa ao júri, funções cívicas ou públicas" ${ }^{34}$. O esforço ia no sentido de investir os tribunais, as escolas, os hospitais e o próprio traçado urbano da cidade de autoridade para dispor da integridade e do significado das liberdades humanas com legitimidade.

Para tanto levou-se em consideração um fenômeno importante: a existência de uma população ignorante das normas mais básicas e gerais dessa nova forma assumida pelo poder. Desde Os sertões de Euclides da Cunha, O Juazeiro de Padre Cícero de Lourenço Filho e o Jeca de Monteiro Lobato sabia-se da existência de toda uma população de gente pobre, "com muito fervor e nenhuma ortografia" ${ }^{35}$. Na década de 1920 a elite ilustrada, que se freqüentava tanto nos salões cariocas, na hípica da Gávea ou nos clubes grã-finos da alta sociedade, como nos cargos administrativos do poder público, deu-se conta da presença dessa gente no próprio sítio conquistado da civilização. O Rio de Janeiro, urbs saneada, capital da República, cidade maravilhosa sentia cada vez mais próximo de si o universo clandestino da civilização. Proximidade que colocava à prova a capacidade de coordenar as tecnologias de planejamento, a divisão do trabalho do frenético período Passos - Frontin, a adaptação da civilização aos trópicos representada pela "obra” de Oswaldo Cruz e, sobretudo, a ordem e o progresso político e social do país. E de fato, as manifestações sociais como os motins e as greves, os novos surtos epidêmicos de febre amarela em 1929, o caráter endêmico da tuberculose e da sífilis no período, as favelas do centro da cidade fechavam, na década de 1920, o círculo prometeico do eterno suplício da civilização dos trópicos.

Por conta dessa situação a República iniciou a montagem de uma estratégia política de orquestração desse suplício. Na verdade, o que surgia na República desse período, muito mais do que na República do século XIX, era a necessidade de fazer com que o ethos social e cultural da elite ilustrada funcionasse também nas margens da sociedade. Tratava-se de conservar no Estado a indiscutível autoridade sobre as formas de controle da ordem social. Procu-

\footnotetext{
${ }^{34}$ PEIXOTO, Afrânio. "A reforma constitucional e a educação". O Jornal. Rio de Janeiro, 11 ago. 1925. p. 01.

${ }^{35}$ LOURENÇO FILHO, Manoel Bergstron. Juazeiro do Padre Cícero. $3^{\mathrm{a}}$ edição, São Paulo: Melhoramentos, s/data.
} 
rava-se um acorde para a República capaz de substituir a dispersão da nação e a corrupção da raça por um momento de harmonia. Creio que o encontraram na prodigiosa condensação entre os verbos regenerar, modernizar e civilizar. Ao dilema euclidiano, progredir ou desaparecer, a geração republicana respondeu com a uníssona recorrência: "mostremos que vivemos"36. Daí se compreende porque a organização administrativa sediada na cidade do Rio de Janeiro, tanto no nível federal quanto municipal, cedeu com facilidade à tentação de instrumentalizar para o conjunto governamental da República os novos ritmos da vida moderna. Era questão de harmonizar a um só tempo os destinos da nação com os da própria civilização. Não obstante, era impor idéias e instituições, atualizar as práticas de expulsão, exclusão e profilaxia sociais em nome do bem comum, era também, engendrar na sociedade práticas de assimilação, inclusão e saneamento do indivíduo marginalizado em relação à "cultura" a que deveria fazer parte, a nacional. E, portanto, trabalho de composição de uma nação.

Estado-regente, a República precisou, no entanto, ensinar sentimentos e habilidades improváveis de se desenvolverem de outro modo que não pela educação. Empenhado na tarefa de "fundar" a unidade nacional procurou extrapolar os contornos propriamente "nosológicos" da regeneração. Nesse momento foi sobretudo necessário educar. O tópico mais celebrado do palavreado progressista do início do século XX voltaria, assim, a baila na voz dos educadores. O "fim primordial da educação", escreveu Zelia Braune em artigo para a revista $A$ Educação, era o de "proporcionar ao organismo sadio condições tais que permitam seu desenvolvimento, impedindo o prejuízo que lhe possa advir de influências estranhas: obstar as más inclinações dos menos perfeitos, evitando a sua queda e a marcha natural para o abismo da enfermidade, da dor e do estiolamento" ${ }^{37}$. A regeneração se faria por meio da cultura. Os grandes planos, as grandes campanhas, passariam pelo planejamento escolar, pelos programas e métodos de ensino. Civilizar foi na década de 1920 educar. Em editorial o Jornal do Brasil deixava-o claro ao reivindicar uma política cultural que começasse por uma difusão da educação primária, essencial para "atalhar a

\footnotetext{
${ }^{36}$ CARDOSO, Vicente Licínio. op. cit., p. 13.

${ }^{37}$ BRAUNE, Zelia. "O fim primordial da educação". A Educação. ano IV, vol. X, n. ${ }^{\circ} 7$ e 8, Rio de Janeiro, jul./ago. de 1925. p. 822.
} 
mortalidade infantil de proporções alarmantes, combater diversas endemias, dar educação pelo menos elementar ao maior número de pessoas, incorporar à atividade e à vida civilizada massas da população"38. Na mesma perspectiva, em entrevista para o Correio da Manhã, o inspetor escolar Deodato de Moraes tornaria público o anseio das orientações que a administração Carneiro Leão procurava dar ao ensino primário, por meio do curso de férias ministrado aos professores do Distrito Federal em 1924, em tornar a criança "um elemento consciente e eficaz no trabalho de civilização"39. Como se si tratasse de um sustenido na escala do progresso, a educação operou uma espécie de atualização do fundamentalismo sanitário, do fervor científico, das distinções culturais e mesmo do charme moderno da elite social, sem falar da sua irresistível inclinação para o autoritarismo anti-liberal. Não esteve sozinha. A instrumentação dos aparelhos de Estado foi completa. A restrição do habeas corpus impingida à Constituição na reforma de 1926 e a formalização do estatuto do menor no Código de Menores em 1927, as noções de saúde e prevenção veiculadas pelas campanhas sanitárias oficiais, a definição urbanista da cidade presente no plano de remodelação de Alfred Agache, a reforma do ensino de 1928 e a criação cultural articulada pelas casas editoriais, galerias de arte e também nas faculdades da capital respondiam a velocidade da produção, a pulsação da cidade, o dinamismo da aprendizagem, a aceleração do progresso, as revoluções estéticas ou políticas e, enfim, o nascimento e a morte do indivíduo a partir de uma válida e completa erudição, desenvolvida com tábuas numéricas, notas de rodapé e terminologia científica. Em meio a essa instrumentação, os criminosos, os bêbados, os doentes mentais, os degenerados morais ou tarados, eram compreendidos como inúteis sociais, peso morto. Tanto quanto eles as criaturas analfabetas ou envolvidas em atividades "clandestinas" comprometiam a ordem e a harmonia da "regência" ou da composição.

De modo que, numa relação de complementaridade entre educação e Estado pode-se aferir, no jogo político republicano, o esforço para ligar toda a população à cidadania e esta aos dispositivos da cultura letrada, da escola pública, do estado nacional e da norma moral, laica ou católica. Procurava-se, sobretudo, dar uma configuração aos procedimentos de inclusão social/naci-

\footnotetext{
${ }^{38}$ Política cultural. Jornal do Brasil, Rio de Janeiro, 26 jan. 1926. p. 1.

${ }^{39} \mathrm{O}$ curso de férias e o seu desenvolvimento. Correio da Manhã. Rio de Janeiro, 10 jan. 1924. p. 3.
} 
onal das populações pobres da capital federal ou as propriedades pedagógicas, médicas, penais ou produtivas de exclusão dos indivíduos analfabetos, doentes, criminosos ou inúteis. Tratava-se de facilitar o controle, de arranjar a petulância normativa da integração social com a democratização do ensino. Para isso a instituição escolar mostrou-se adequada. Não somente como sistema de vigilância, escrituração, inscrição e inspeção mas em razão das suas tecnologias de avaliação e exame a escola fora compreendida como a instância adequada para identificar, corrigir ou eliminar qualquer tipo de dissonância que atrapalhasse a harmonia social. Desejo de fazer a civilização penetrar os subúrbios sim mas também, tentativa de determinar na escola o pólo imanente para aqueles que queriam se educar e progredir, as reformas da década de 1920 insistiram na integração entre as estratégias pedagógicas, as formas escolares e a racionalidade científica no desenvolvimento de uma política educacional. Ao que correspondeu tanto um modelo escolar capaz de atar a formação individual à finalidades cívicas e culturais quanto o uso científico dos saberes pedagógicos para atualizar os dispositivos escolares de educação. Esse modelo foi proposto à instrução primária das crianças no intuito de assegurar uma educação conveniente ao povo. Deveria para tanto não só ensinar a ler e escrever, ou manifestar signos de sociabilidade, mas sobretudo, impedir a licenciosidade ou promiscuidade, burguesa ou proletária, do caráter por parte das crianças, controlar a conduta, os hábitos e a moral dos alunos, delinear procedimentos de vigilância e exame capazes de fazer distinguir o certo do errado ou o dever da infração aos futuros cidadãos e, também, estabelecer práticas de correção, punição ou, conforme o caso, legitimação e incentivo das ações discentes. E assim o fez.

A forma assumida pela escola nas reformas Carneiro Leão e Fernando de Azevedo esteve ligada a estratégias de educação dirigidas para a produção de limpeza, razão, estilo de vida, cultura e disciplina na sociedade carioca (alter ego da brasileira) e, portanto, a uma materialidade investida de um novo estatuto pedagógico, não somente corretivo - disciplinar mas sobretudo sócio cultural, não só ortopedia físico - mental, mas prédica social. É dizer que ao lado das preocupações pedagógicas com os materiais usualmente empregados no ensino, a ordem e a disciplina do corpo discente e, a disposição do espaço escolar e dos cuidados com as condições materiais capazes de resguardar as crianças dos riscos da miséria operária ou da opulência burguesa, das doenças contagiosas ou infecciosas, do aglomerado urbano e, principalmente, da concorrência moral na apropriação ou produção da cultura "legítima" dada pela escola, ajuntou-se a tarefa de consolidar um sistema de transmissão do 
saber vinculado a aparelhos de formação e correção eficientes na adaptação e qualificação dos alunos à sociedade.

A reforma Carneiro Leão procurou cumpri-la preparando para a vida moderna, a reforma Fernando de Azevedo, adaptando-a para um tempo em mudança. Todavia, ambas se encontraram numa idéia cardeal: recuperar a vida do dia a dia para a escola, reunir a escola e a vida, reconquistar uma para outra, e assim criar um domínio próprio para a educação do corpo, da mente e do espírito. A novidade das reformas da instrução na década de 1920 consistiu justamente em fazer da escola esse domínio. Nela reuniram espaços de disciplina e operações de controle capazes de funcionar como estratégias de emancipação do indivíduo e da nação. Por meio de políticas de assistência social, dos serviços médicos, de clínica e inspeção, da aplicação de testes de inteligência, de demonstrações públicas de cultura física e sobretudo com Fernando de Azevedo, da implementação de uma política de edificações escolares subordinada às regras da higiene escolar, da técnica pedagógica e da estética "nacional", produziram formas sólidas para a panóplia escolar de correção e formação da criança. De modo que, não tanto a alfabetização mas a correção da conduta cotidiana forneceria às crianças o comportamento social adequado ao pleno exercício da cidadania.

\section{Considerações finais}

Não espanta, portanto, o tipo humano ocupar um papel central no planejamento da arquitetura, dos programas e das instalações escolares. Nele esteve em jogo, entretanto, algo mais do que a solicitação das forças que o próprio indivíduo dispunha no corpo. Havia também uma sofisticação das coações sobre a sua liberdade frente à coletividade.

As reformas da instrução na capital da Velha República durante a década de 1920 foram mais uma conseqüência do que o ponto de partida dessa situação. A escola elementar colocou em ação intervenções constantes e obstinadas no controle das experiências da criança. Pronunciava-se pelo desengano da consciência e pelo constrangimento do corpo. Entretanto, agia por meio do "jogo" e da "brincadeira". E de fato, as reformas procuraram sintetizar nos seus programas os elos que encadeavam a civilização, corrigir por meio de suas instalações as patologias sociais, médicas ou psicológicas sem encerrar o corpo num molde ou disciplinar pela coação. Sua arquitetura deveria facilitar a vigilância, mas também produzir prazer estético, tranqüilidade e gozo. 
De certo modo para os reformadores da década de 1920 a educação capaz de moldar e sustentar o corpo não se objetivava em outro lugar que a comunidade. Ela e não os procedimentos mecânicos do Estado, policiais ou instrumentais, deveriam constranger a ação do indivíduo em sociedade. Nessa educação as escolas revelavam a obsessão da vida existente nas reformas da instrução. Revelavam como elaborar o Brasil já em plena modernidade. "Sobre as ruínas dos erros acumulados" fez se da educação pública na capital do país um problema cuja solução interessava à própria vida do país ${ }^{40}$. Dela resultou a cunhagem de uma "nova" escola, indispensável à vitória na luta pela vida, adequada ao desenvolvimento da cultura geral e organizada dentro da vida social ${ }^{41}$. O que eqüivale a dizer que as reformas converteram em dilema o que era doutrina quando multiplicaram os meios de controle da subjetividade infantil. A escolha implicada no dilema educar-se ou desaparecer enunciado por Fernando de Azevedo logo após sua posse no cargo de diretor geral da instrução, não só informava a doutrina pedagógica com a áspera realidade nacional como estigmatizava aqueles que rejeitando o propósito e o significado da "nova civilização" comprometiam a ordem e a harmonia do corpo social.

Ao observar-se as diversas representações sobre a escola primária, veiculadas pelas reformas Carneiro Leão e Fernando de Azevedo, pode-se distinguir um empreendimento intoxicado de política, de poder e de Estado. Essa característica das reformas conferiu à escola passagens "velozes" entre seu sistema pedagógico e as preocupações políticas e sociais com a organização do trabalho, a manutenção da saúde e a identificação e seleção das inteligências. Convencida da regeneração por meio da educação, as reformas condensaramna nos domínios fisiológicos, psicológicos e sociológicos. Ou seja, procuraram integrar a escola ao meio, o indivíduo à sociedade - adaptar o indivíduo ao meio, fazer da escola um lugar capaz de reunir a "comunidade" em torno de sua origem, ou melhor, da narrativa na qual ela deveria se reconhecer. Em última instância contrapor às tradições populares aquilo que Fernando de Azevedo cha-

\footnotetext{
${ }^{40}$ AZEVEDO, Fernando de. Novos caminhos e novos fins: a nova política de educação no Brasil. op. cit., p. 57.

${ }^{41}$ AZEVEDO, Fernando de. A socialização da escola. op. cit., p. 9 e 23; CARNEIRO LEÃO, Antônio. O ensino na capital do Brasil. op. cit., p. 7.
} 
mou de "a consciência profunda das necessidades nacionais". Era, de fato, conferir à escola o estatuto de "aparelho dinâmico de ação e reação conscientes" Não se tratou nem de uma arte, nem de uma técnica, antes de um fim. Na verdade três. Primeiro, a regência das formas responsáveis pela harmonia entre a interioridade individual e o comportamento social. Segundo, a erradicação dos detritos da modernidade, seus distúrbios, seus excessos. E, finalmente, a construção de uma nação, limpa e ordenada, se se quiser, mais apropriada aquilo que se considerava vida humana adequada. Finalidades essas que diziam "civiliza-se ou desaparece". Em suma, tratava-se de cuidar da única condição prática, positiva e utilitária da vida: aformosea-la ${ }^{43}$.

\footnotetext{
${ }^{42}$ AZEVEDO, Fernando de. Novos caminhos e novos fins: a nova política de educação no Brasil. op. cit., p. 52 e 118.

${ }^{43}$ AZEVEDO, Fernando de. A reforma do ensino no Districto Federal: discursos e entrevistas. op. cit., p. 75.
} 